\title{
Challenges and Opportunities for Recycled Polyethylene Fishing Nets: Towards a Circular Economy
}

\author{
Rafael Juan ${ }^{1,2}$ D, Carlos Domínguez ${ }^{1,2, *}$, Nuria Robledo ${ }^{1,2}$, Beatriz Paredes ${ }^{1,2}$, Sara Galera ${ }^{3}$ \\ and Rafael A. García-Muñoz 1,2,*(D)
}

1 LATEP, Polymer Technology Laboratory, Rey Juan Carlos University, Tulipán St., Móstoles, 28933 Madrid, Spain; rafael.juan@urjc.es (R.J.); nuria.robledo@urjc.es (N.R.); beatriz.paredes@urjc.es (B.P.)

2 GIQA, Group of Environmental and Chemical Engineering, ESCET, Rey Juan Carlos University, Tulipán St., Móstoles, 28933 Madrid, Spain

3 REPSOL, Repsol Technology Lab, Agustin de Betancourt St., Móstoles, 28935 Madrid, Spain; sara.galera@repsol.com

* Correspondence: carlos.dominguez@urjc.es (C.D.); rafael.garcia@urjc.es (R.A.G.-M.)

check for

updates

Citation: Juan, R.; Domínguez, C.; Robledo, N.; Paredes, B.; Galera, S.; García-Muñoz, R.A. Challenges and Opportunities for Recycled Polyethylene Fishing Nets: Towards a Circular Economy. Polymers 2021, 13, 3155. https://doi.org/10.3390/ polym13183155

Academic Editor: Abdel-Hamid I. Mourad

Received: 29 August 2021

Accepted: 15 September 2021

Published: 17 September 2021

Publisher's Note: MDPI stays neutral with regard to jurisdictional claims in published maps and institutional affiliations.

Copyright: (c) 2021 by the authors. Licensee MDPI, Basel, Switzerland. This article is an open access article distributed under the terms and conditions of the Creative Commons Attribution (CC BY) license (https:/ / creativecommons.org/licenses/by/ $4.0 /)$.

\begin{abstract}
Plastic waste generation has become an important problem that critically affects marine and oceans environments. Fishing nets gear usually have a relatively short lifespan, and are abandoned, discarded and lost, what makes them one of the largest generators of ocean plastic waste. Recycled polyolefin resins from fishing nets $(\mathrm{rFN})$, especially from polyethylene (PE), have poor properties due to the presence of contaminants and/or excessive degradation after its lifetime. These reasons limit the use of these recycled resins. This work aims to study the incorporation of recycled fishing nets PE-made to different grades of virgin PE, in order to evaluate the potential use of these rFN in the development of new products. The recovered fishing nets have been fully characterized to evaluate its properties after the collection and recycling process. Then, different PE virgin resins have been mechanically blended with the recovered fishing nets at different recycling contents to study its feasibility for fishing nets or packaging applications. Critical mechanical properties for these applications, as the elongation at break, impact strength or environmental stress cracking resistance have been deeply evaluated. Results show important limitations for the manufacture of fibers from recycled PE fishing nets due to the presence of inorganic particles from the marine environment, which restricts the use of $\mathrm{rFN}$ for its original application. However, it is proved that a proper selection of PE raw resins, to be used in the blending process, allows other possible applications, such as non-food contact bottles, which open up new ways for using the fishing nets recyclates, in line with the objectives pursued by the Circular Economy of Plastics.
\end{abstract}

Keywords: recycled fishing nets (rFN); recycled polyethylene; high-density polyethylene (HDPE); circular economy

\section{Introduction}

Plastics have become ubiquitous materials in our lives with a wide range of applications thanks to their excellent properties and low cost of production. Recent reports estimate that around 50.7 million tonnes of plastics were demanded in Europe in 2019 [1]. These resins are used to manufacture a wide range of products, mainly in the packaging $(39.6 \%)$ and construction $(20.4 \%)$ sectors. However, with the exponential growth of plastic resins production, plastic pollution has become an important issue for countries and ecosystems around the globe, and especially for marine environments [2-4]. According to recent reports, is estimated that around 11 million metric tons of plastic debris ends into the oceans every year, and is expected that without additional measures or actions, this flow of plastics litter will nearly triple in 2040 (around 29 million metric tons per year) [5]. From this source of plastic waste, over $80 \%$ was originated from land, while the rest is related to marine activities [6]. Measures have been currently adopted by governments 
and industries to reduce plastic debris from land [7,8]. However, those related to marine activities are still a challenge due to the difficulty to collect this plastic waste and the mismanagement of discarded fishing gear.

In Europe, goods related to fishing activities (Abandoned, Lost or otherwise Discarded Fishing Gear-ALDFG) are listed among the 10 most common debris found on coasts and beaches (27\% of total litter) [9]. Additionally, fishing goods have usually a short lifetime that together with their loss at oceans and seas produces that around 640,000 tonnes of fishing gear are discarded globally every year [10], although the underestimation about the real metrics of abandoned fishing gear could hinder the real impact of these source of contamination [11]. These debris lead not only to important effects on marine flora and fauna due to plastic consumption and "ghost fishing" [12,13], but also cause and striking economic and social harm [14]. To combat this concern and reduce the plastic pollution at marine environments, important resources are being employed to develop new ways to reduce, reuse and recycle these products [15], under the objective to achieve a Circular Economy and the guidelines adopted in this sense by the European Union Council [16].

Nevertheless, recycling of fishing goods is not an easy task, as they are made from different plastics, mostly from polyamide (PA), polyethylene (PE), and polypropylene (PP) [17]. In particular, high-quality polymers need to be used to manufacture these items owing to strict requirements of most fishing gear, specifically the fishing nets. Among these resins, recycling rates differs depending on their ease of recycling and availability. PA is extensively used, mainly for manufacturing of gill nets due to its toughness and elasticity. Discarded fishing nets from PA are currently both mechanical [18] and mainly chemically recycled via depolymerization [19]. Chemical recycling allows transforming nylon nets back into recycled materials, obtaining a yarn that could be used in the manufacture of clothing or in the development of several new products [20].

On the other hand, fishing nets from PE and PP polyolefins have a lower value, as both are usually used to produce trawl nets, which suffer from abrasive damage [21]. Another important concern that must considered by the recyclers is the habitual presence of organic matter [22], which requires an exhaustive cleaning step that increase the economic costs of the process. For this reason, recycled resins from these materials usually have a lower performance and makes them difficult to compete with their virgin counterpart [23]. Most research have focused on the use of these recyclates as reinforcements fibers for construction applications [24-26] since their use as a main material for the manufacture of new products with the same application has been previously rejected due to their poor mechanical performance [27].

Several companies are producing recycled PA, HDPE, and PP from fishing net materials, via mechanical recycling [28,29]. Even if a sorting and separation step is essential to improve the properties of the recycled resins obtained, mechanical recycling of fishing net could still be a viable way of using these recycled plastics in the industry. To improve their properties and extend their use as a recycled material, blending with raw resins at different percentages could guarantee the requirements for the desired applications. Blending of virgin and recycled materials was demonstrated to be a feasible strategy to reuse plastic resins and help the development of a Circular Economy of Plastic [30-32].

The objective of this work is to study the incorporation of recycled polyethylene obtained from fishing nets to different grades of virgin PE (Figure 1). Although one of the aims is to obtain a blending material that can be used again in the manufacture of fishing nets, considering the properties of the recycled material, other potential applications related to bottle packaging were explored. The homogeneity and possible presence of contaminants in the recycled material were determined through Fourier Transform Infrared Spectroscopy (FTIR), Differential Scanning Calorimetry (DSC), Thermogravimetric Analysis (TGA) and Temperature Rising Elution Fractionation (TREF) measurements. These techniques, together with Gel Permeation Chromatography (GPC) and rheological measurements, were also used to study the chemical composition and homogeneity of all blends prepared. Mechanical properties were established by tensile, flexural and impact 
tests. The Environmental Stress Cracking Resistance (ESCR) of these blends was also evaluated to overall determine the long-term performance of these materials and their suitability for fishing nets and packaging applications.

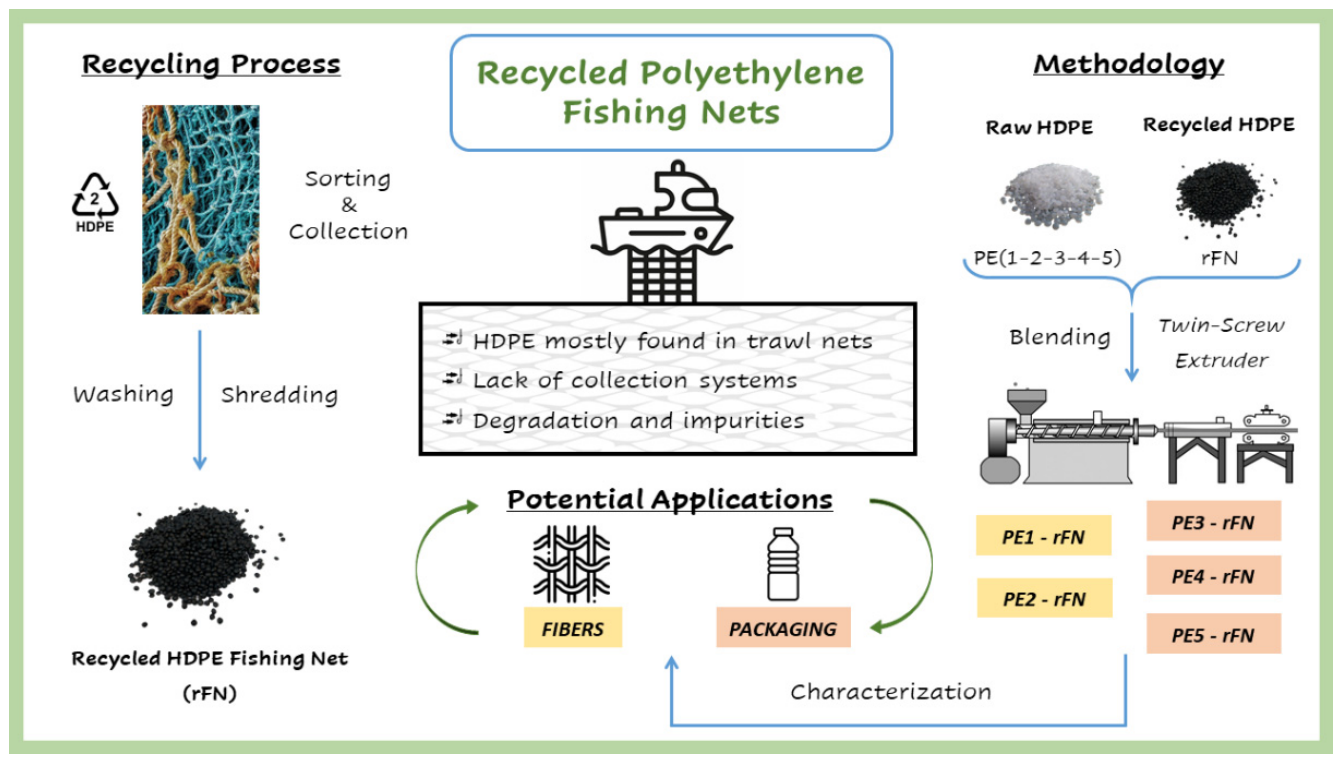

Figure 1. Flowchart of the experimental procedure.

\section{Materials and Methods}

\subsection{Materials}

Discarded HDPE fishing nets from Spanish harbors were sorted and separated from other polymers such as PA and PP to reduce cross contamination. Once collected, they were washed and cleaned, shredded, and extruded to obtain homogeneous pellets from these recycled HDPE fishing nets $(\mathrm{rFN})$. This recyclate was blended with five raw resins used in different applications such as in fibers and packaging products. The blending process has been carried out in a Collin ZK 50 counter-rotating twin-screw extruder, containing up to $75 \mathrm{wt} . \%$ of $\mathrm{rFN}$, and the corresponding raw resin for the remaining portion. The extrusion temperature goes from 185 to $240^{\circ} \mathrm{C}$ with a screw speed of $60-80 \mathrm{rpm}$.

\subsection{Molecular and Physical Characterization}

To characterize the molecular structure of the resins, molecular weight $(\mathrm{Mw})$, molecular weight distribution (MWD), and short chain branching (SCB) distribution were determined on a high temperature Gel Permeation Chromatography (GPC) GPC-IR6 (Polymer Char). The set of columns and infrared detector equipped on the GPC-IR6 allows distinguishing differences of 1 branch per 1000 atoms of carbon. Samples were dissolved in 1,2,4-trichlorobenzene (TCB) stabilized with BHT (2,6-di-tert-butyl-4-methylphenol) at a concentration of $0.75 \mathrm{mg} / \mathrm{mL}$. The flow rate and temperature for the analysis was $1.0 \mathrm{~mL} / \mathrm{min}$ and $160^{\circ} \mathrm{C}$, respectively.

TREF experiments were carried out on a commercial CRYSTAF-TREF instrument model 300 (Polymer Char). Samples of $80 \mathrm{mg}$ were dissolved in TCB at $160{ }^{\circ} \mathrm{C}$. After $60 \mathrm{~min}$. of gentle stirring, the solution was injected into the column and held at $130^{\circ} \mathrm{C}$ for $45 \mathrm{~min}$. Then, the temperature decreased from 130 to $35^{\circ} \mathrm{C}$ at a cooling rate of $0.5^{\circ} \mathrm{C} / \mathrm{min}$ to allow the polymer crystallization into the column. In the final step, the sample was eluted at a constant flow rate of $1 \mathrm{~mL} / \mathrm{min}$ while rising the temperature from 35 to $140{ }^{\circ} \mathrm{C}$. The polymer concentration was measured by an infrared detector and the crystallization curves were obtained from the first derivative.

Thermal measurements were developed at a heat rate of $10{ }^{\circ} \mathrm{C} / \mathrm{min}$ with a DSC Mettler-Toledo 822e. Additionally, thermal stability of the recycled material was evaluated 
using a TGA/DSC 1 thermogravimetric analyzer (Mettler-Toledo), from $20{ }^{\circ} \mathrm{C}$ to $600{ }^{\circ} \mathrm{C}$ at a heating rate of $20^{\circ} \mathrm{C} / \mathrm{min}$.

FTIR spectra were collected in attenuated total reflection (ATR) mode using a FT-IR Varian Excalibur 3100 spectrometer. The analysis was performed at room temperature and ambient humidity between 4000 and $400 \mathrm{~cm}^{-1}$, with 64 scans. The spectra were obtained in transmittance mode.

Rheological measurements were performed in a TA Instruments (model DHR-2) rheometer in the parallel plate mode. Sheets of around $2 \mathrm{~mm}$ of thickness have been previously compression molded and disks of suitable dimensions for rheological measurements have been obtained. The oscillatory viscoelastic determinations were carried out over the frequency range $0.01-100 \mathrm{rad} \cdot \mathrm{s}^{-1}$. Deformation was set at around $1 \%$, which corresponds to the linear viscoelastic region in all the pure polymers and blends, identified through previous amplitude sweeps. The measurements were performed at $190^{\circ} \mathrm{C}$.

Tensile and flexural tests were developed in a universal testing machine (MTS Alliance RT/5) at $23{ }^{\circ} \mathrm{C}$ and $50 \%$ relative humidity. Tensile tests were carried out using dumbbell shaped specimens 1BA at a crosshead speed of $50 \mathrm{~mm} / \mathrm{min}$, according to UNE-EN ISO 527-2:2012. Flexural and Charpy impact tests were performed on rectangular bars samples measuring $80 \mathrm{~mm} \times 10 \mathrm{~mm} \times 4 \mathrm{~mm}$, extracted from a plate previously molded by compression. Flexural tests were carried out with a three-point bending geometry according to the ISO 178:2010 standard at a crosshead speed of $2 \mathrm{~mm} / \mathrm{min}$, while Charpy impact tests were done following the UNE-EN ISO 179-1:2010.

\subsection{Environmental Stress Crack Resistance (ESCR)}

Environmental stress cracking resistance was evaluated according to ASTM D 1693-15, under test condition B: Surface-active agent (Igepal CO-630) concentration of 10\% volume in water at $50^{\circ} \mathrm{C}$. The tested materials have been previously obtained via compression molding.

\section{Results and Discussion}

The potential use of recycled HDPE fishing nets for different applications were evaluated through its blending with different raw resins. Table 1 summarizes the main physicochemical properties of the materials used in this work and the main application of the raw resins (fibers or packaging products).

Table 1. Physicochemical properties of raw resins and recycled fishing net $(\mathrm{rFN})$.

\begin{tabular}{cccccc}
\hline Material & Type & Mw (kg/mol) & Mw/Mn (-) & SCB/1000C & Tm $\left({ }^{\circ} \mathbf{C}\right)$ \\
\hline PE1 & \multirow{2}{*}{ Fibers } & 149 & 6.94 & 1.3 & 140.0 \\
PE2 & & 146 & 8.42 & 2.1 & 139.5 \\
PE3 & Packaging & 209 & 29.7 & 0.3 & 132.4 \\
PE4 & & 348 & 38.7 & 0.3 & 132.5 \\
PE5 & 274 & 22.6 & 1.0 & 130.3 \\
rFN & Recycled HDPE & 121 & 8.40 & 2.5 & 138.0 \\
& Fishing Net & & & & \\
\hline
\end{tabular}

Blends of virgin and recycled materials have been prepared using a counter-rotating twin-screw extruder to achieve a better homogenization and incorporating the recycled material at different rates (up to $75 \%$ of recycled resin). Each system prepared has been named according to the virgin resin and the recycled content (namely PEX-rFN-Y; where $X$ corresponds to raw resin 1, 2, 3, 4 or 5; and Y corresponds to wt.\% of recycled fishing net).

\subsection{Blends for Fishing Nets Gear Application}

The first objective of this study is to evaluate the potential use of these recyclates for the manufacture of fishing nets gear. Within this goal, two virgin resins have been chosen, named PE1 and PE2, respectively. These raw materials have been selected as they are 
typically used in the manufacture of fibers and nets, thus with similar properties to the recycled resin.

All blends were characterized by GPC and DSC to assess that blending process was successfully accomplished. Table 2 summarizes the results obtained for both systems (PE1-rFN and PE2-rFN). Both raw resins have a slightly higher Mw than rFN (Table 1). It is noteworthy that recycling process and degradation normally causes a drop in $\mathrm{Mw}$ for recycled materials [33]. Moreover, discarded fishing gear are greatly exposed to environmental conditions, being seriously affected by factors like ultraviolet light (UV) and temperature, which favors the degradation process [34]. The difference between the virgin PEs lies on their MWD and SCB distribution, being PE2 MWD slightly broader and with a higher SCB content than that of the PE1 resin. During the blending process, a progressive decrease in the $\mathrm{Mw}$ with the increasing of the rFN content is observed, for both systems. A broadening of the MWD is also observed, probably caused by the blending and extrusion process. Melting temperatures, for all blends prepared, were placed between the melting point of raw and $\mathrm{rFN}$ materials $\left(140.0\right.$ and $139.5^{\circ} \mathrm{C}$ for PE1 and PE2, and $138{ }^{\circ} \mathrm{C}$ for the recycled material). Moreover, the melting peak slightly shifted to lower temperatures with the increasing content of $\mathrm{rFN}$. All these results indicate a good miscibility among the virgin and recycled materials, which confirms that the blending process was effective and a good compatibility among all polyethylene resins was achieved.

Table 2. GPC and DSC results for PE1—rFN and PE2-rFN blend systems.

\begin{tabular}{ccccc}
\hline Blend System & \% rFN & Mw $\mathbf{~ k g / m o l ) ~}$ & Mw/Mn (-) & Tm $\left({ }^{\circ} \mathbf{C}\right)$ \\
\hline & 0 & 149 & 6.94 & 140.0 \\
PE1-rFN & 10 & 147 & 7.17 & 140.2 \\
& 15 & 144 & 7.19 & 138.8 \\
& 25 & 139 & 7.56 & 137.9 \\
& 50 & 135 & 8.42 & 137.4 \\
PE2-rFN & 100 & 121 & 8.40 & 138.0 \\
& 0 & 146 & 8.42 & 139.5 \\
& 10 & 141 & 8.50 & 138.9 \\
& 15 & 141 & 8.93 & 138.5 \\
& 25 & 138 & 8.68 & 137.9 \\
& 50 & 132 & 9.00 & 138.1 \\
\hline
\end{tabular}

After addressing the blend compatibility, the influence of the incorporation of rFN to virgin resins have been studied through the characterization of mechanical properties. Tensile stress-strain curves, flexural modulus and impact strength resistance were determined for both blend systems at room temperature (Figure 2a-d, respectively). At lower recycled contents (10 and $15 \mathrm{wt} . \%$ ), tensile strength (Figure 2a) and elongation at break (Figure $2 \mathrm{~b}$ ) are little affected, with values close to those obtained for both raw resins. However, for higher recycled contents these properties are more affected compared to those of both virgin materials, with a greater dispersion of the measurements. $r F N$ shows lower values and close to half of those observed for both raw resins. These facts could be explained due to the decrease in $\mathrm{Mw}$ with the increasing $\mathrm{rFN}$ content. Flexural modulus is less affected by the presence of the recycled net, with values between 1200 and $1300 \mathrm{MPa}$ for all blends (Figure 2c). Finally, impact strength resistance is greatly affected by the incorporation of the recycled material, especially for the system "PE1—rFN", which have a higher initial

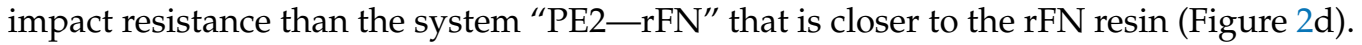


(a)

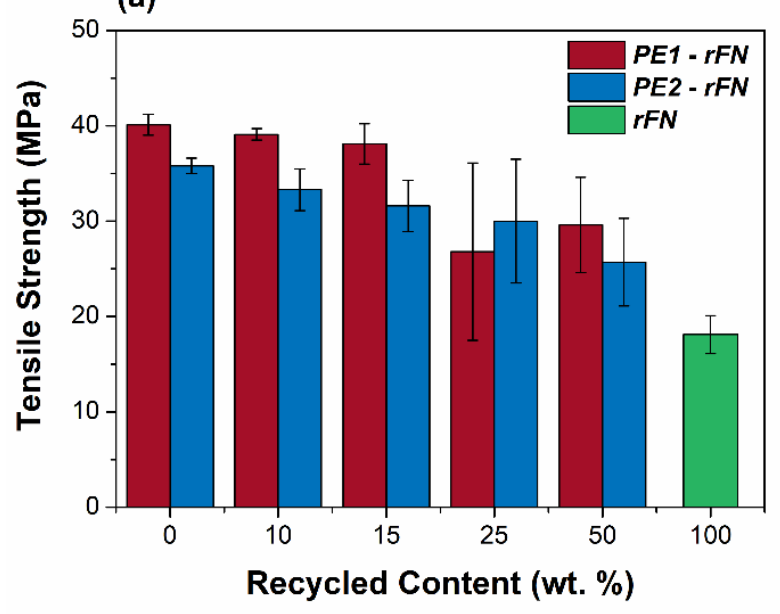

(c)

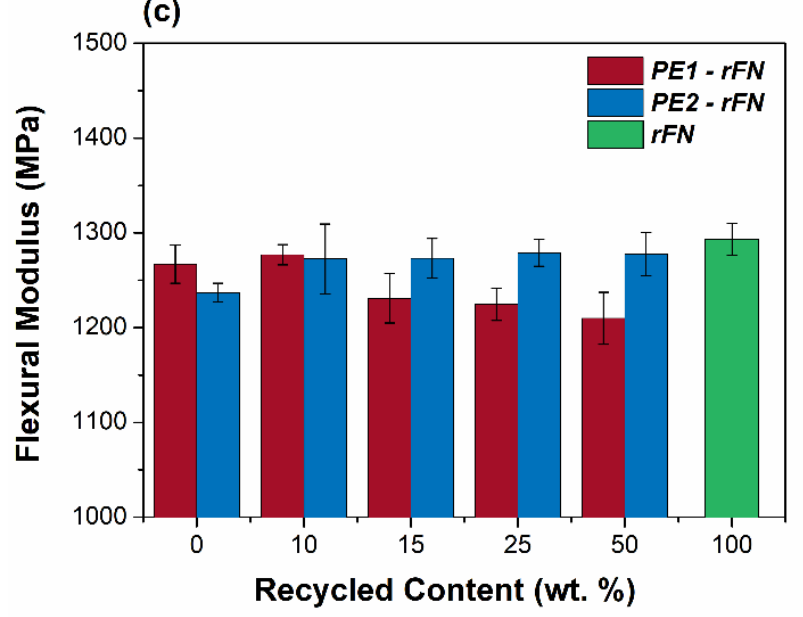

(b)

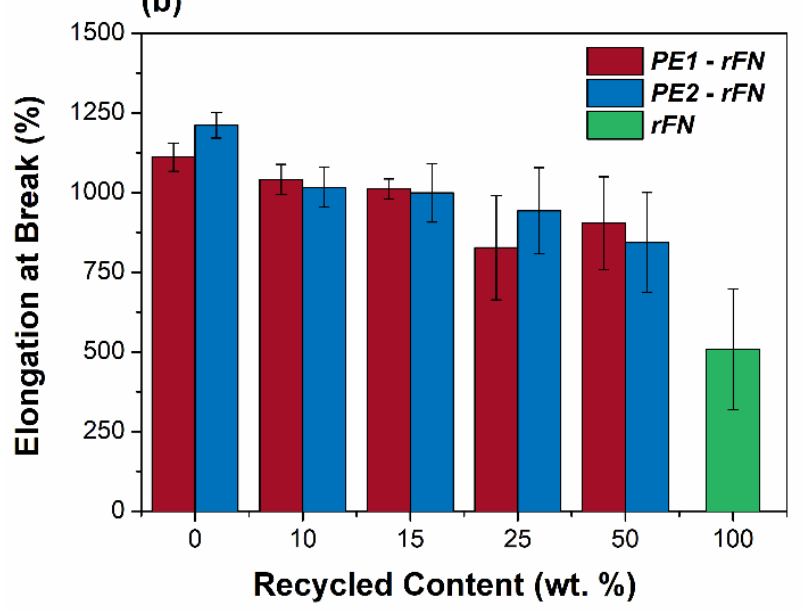

(d)

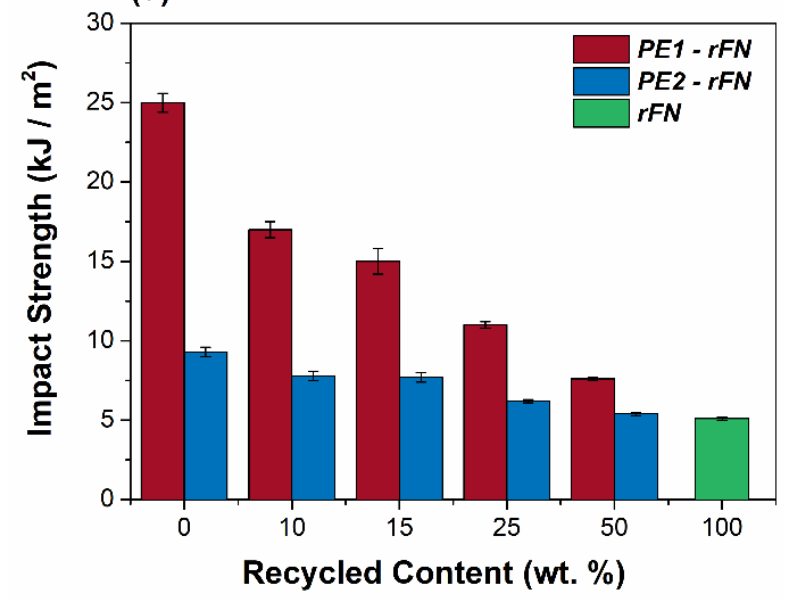

Figure 2. (a) Tensile strength, (b) Elongation at break, (c) Flexural modulus and (d) Impact strength resistance results for PE1—rFN and PE2—rFN systems.

Moreover, cross contamination with other polymers or inorganic impurities could also be the cause of the premature rupture of the specimens during tensile tests since this is a common phenomenon for recycled polyolefins [35] that may also affect its longterm performance [36]. To confirm if the presence of unwanted substances could be the reason of the results obtained, further tests were performed for the rFN resin. Figure 3 shows the FTIR spectrum obtained for the rFN material. First, a doublet corresponding to asymmetric $\left(2914 \mathrm{~cm}^{-1}\right)$ and symmetric $\left(2848 \mathrm{~cm}^{-1}\right)$ stretching of $\mathrm{CH}_{2}$ are observed. Two more doublets are seen at 1470 and $725 \mathrm{~cm}^{-1}$, which correspond to bending and rocking deformations, respectively. All these peaks confirm the presence of PE [37]. No other signals are obtained in the spectrum, which could indicate that the separation from other fishing nets was effective.

To further verify that cross contamination with other polymers did not take place during the recycling process, DSC and TREF analyses were performed (Figure 4). The DSC thermogram reveals a single melting peak at $138^{\circ} \mathrm{C}$, which corresponds to PE. No other melting peaks are observed, neither at $160{ }^{\circ} \mathrm{C}(\mathrm{PP})$ nor at $220^{\circ} \mathrm{C}$ (PA-6) [38], which confirms the homogeneity of the recyclate and the successful previous separation process. However, DSC analysis is not really confident for the determination of PP contents under 2 wt.\%, and TREF analyses were performed. TREF allows fractionating different polymer chains as functions of their crystallinity to understand the microstructure and the phase behavior of these materials. This technique, commonly used to determine the chemical composition distribution of different polymer blends, has recently proven to be more 
accurate for detection and quantification of PP impurities at low quantities than standard methodologies [39]. The thermograms reveals a main region between 90 and $105{ }^{\circ} \mathrm{C}$ composed by a very intense peak, which corresponds to the crystalline fraction of the HDPE chains $\left(100^{\circ} \mathrm{C}\right)$. The absence of other peaks, especially in the range of $120^{\circ} \mathrm{C}$, which corresponds to PP region, confirms that no or negligible cross contamination occurred during the recycling process [40].
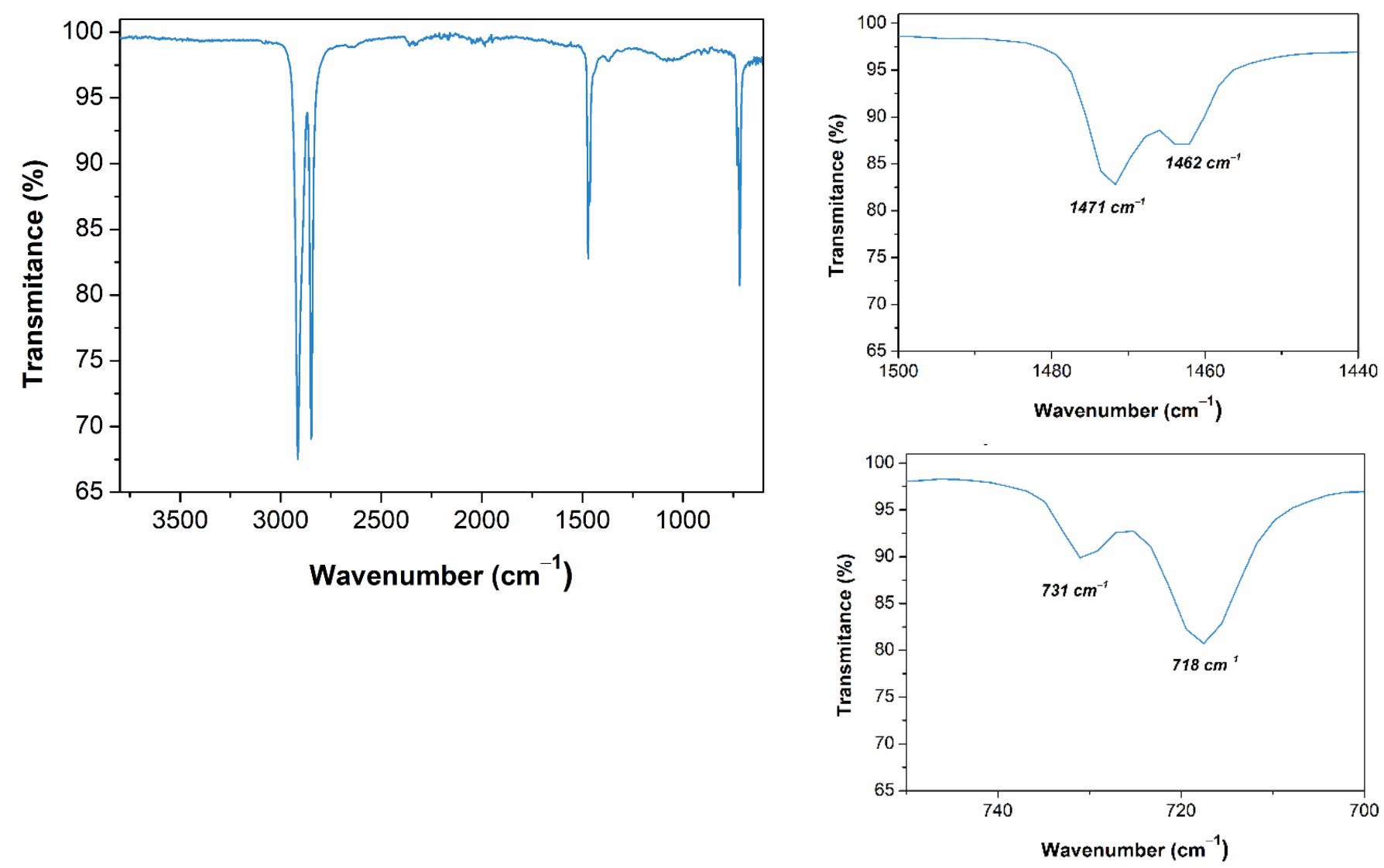

Figure 3. FTIR Spectrum of the recycled fishing net (rFN).

(a)

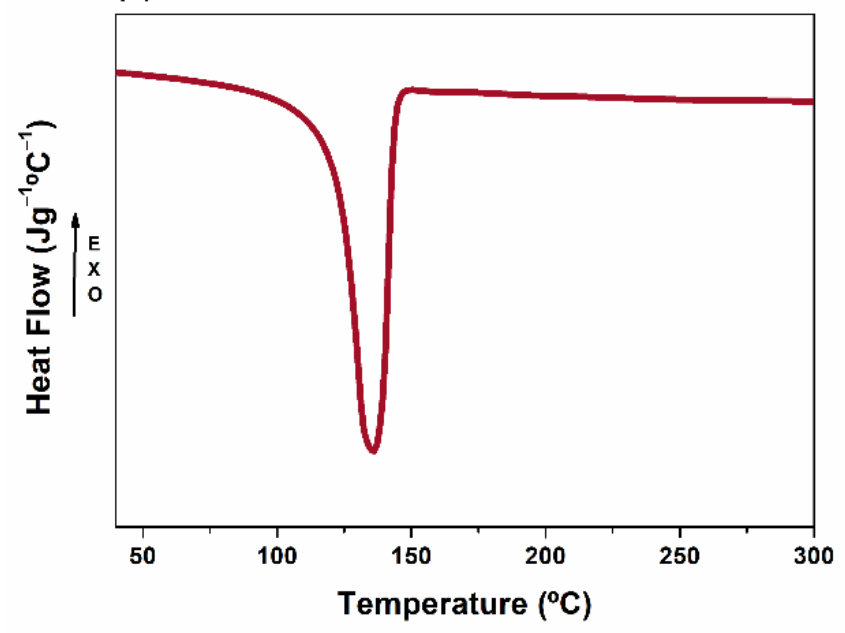

(b)

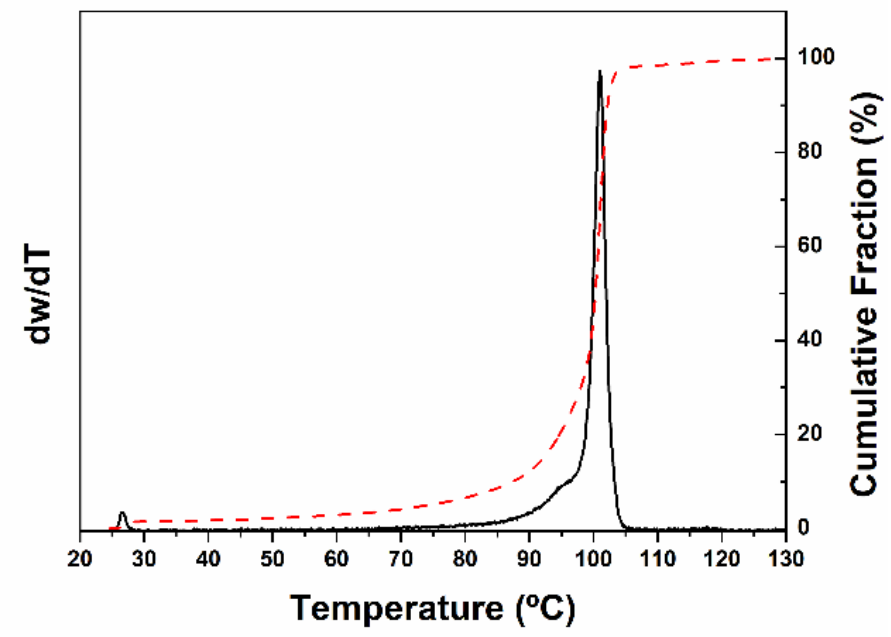

Figure 4. (a) DSC melting thermogram and (b) TREF curves for the recycled fishing net (rFN). 
Finally, the thermal stability of rFN was evaluated through thermogravimetric analysis (Figure 5). The results show a residue around $6 \mathrm{wt} . \%$, which could be assigned to the presence of $\mathrm{CaCO}_{3}$ (fillers). However, this residual high value in the sample also could indicate the presence of other inorganic contaminants (mainly silicates) present in marine environments. The presence of these impurities, even after the recycling process for the obtention of rFN, reveals the difficulty of washing and cleaning these kinds of recycled materials.

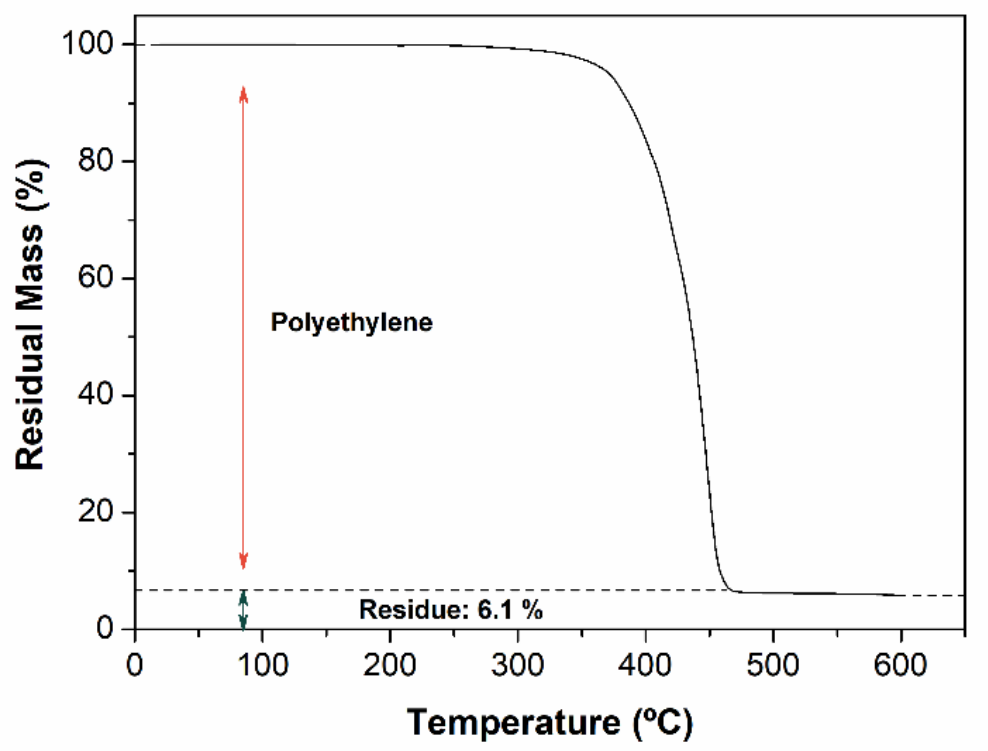

Figure 5. TGA curve for the recycled fishing net.

The presence of undesirable particles in the recycled samples may explain the results obtained during the mechanical characterization of both systems (PE1 - rFN and PE2$\mathrm{rFN}$ ), as key properties such as elongation at break or impact strength resistance are greatly affected by the presence of contaminants. This fact clearly endangers its possible use in the manufacture of fishing nets gear since the presence of impurities could act as a stress riser and fracture initiator that may break the fibers during the manufacture and failing in the process of obtaining monofilaments and nets. As a result, $\mathrm{rFNs}$ do not seem suitable for the original application and strengthening us to search for other possible uses for this recycled material.

\subsection{Blends for Packaging Application}

The results attained for PE1-rFN and PE2-rFN ascertained its limited use in the manufacture of fishing nets, mainly due to the contamination present in the recycled resin. However, the overall properties obtained for the recycled materials could be useful for other applications. As previously mentioned, packaging industries are one of the biggest consumers of PE resins. The European regulations and objectives regarding Circular Economy of Plastics are expecting to incorporate recycled resins in packaging sector to reduce the raw plastic consumption in the next few years [41]. Within this aim, we have evaluated the recycled fishing nets as a possible recyclate source for the manufacture of non-food contact bottles, such as those used to contain cleaning or cosmetic products.

Three high-molecular weight blow molding raw HDPE resins have been chosen (named PE3, PE4 and PE5), in order to reinforce the expected loss of properties after blending with the recyclate. In this sense, the use of other additives or compatibilizers was avoided, as its use could increase the economic cost of the process hindering their recyclability [42]. Thermal and molecular characterization were carried out for all blending systems (PE3-4-5-rFN). Results are summarized in Table 3. All virgin resins have higher $\mathrm{Mw}$ and broader distributions than the rFN material. As the content of rFN increases 
the $\mathrm{Mw}$ of the blend decreases, and the distribution is becoming narrower. Both aspects suggest a good compatibility between both virgin and recycled resins, which is supported by the DSC curves that show a single melting peak for all systems (Table 3). Regarding the melting temperature, all blend systems appear to shift to higher temperatures with the increasing content of $\mathrm{rFN}$, respecting the virgin PEs, which also implies good miscibility among the components.

Table 3. GPC and DSC results for PE3-rFN, PE4—rFN and PE5—rFN blend systems.

\begin{tabular}{ccccc}
\hline Blend System & \% rFN & Mw $\mathbf{~ ( k g / m o l ) ~}$ & Mw/Mn $(-)$ & Tm $\left({ }^{\circ} \mathbf{C}\right)$ \\
\hline & 0 & 205 & 22.1 & 132.4 \\
& 10 & 202 & 20.6 & 133.9 \\
PE3-rFN & 15 & 201 & 20.1 & 133.5 \\
& 25 & 193 & 18.9 & 135.9 \\
& 50 & 175 & 15.1 & 136.7 \\
& 75 & 147 & 13.2 & 137.1 \\
& 100 & 121 & 8.40 & 138.0 \\
\hline & 0 & 348 & 38.7 & 132.5 \\
PE4-rFN & 10 & 307 & 34.7 & 133.5 \\
& 15 & 307 & 33.2 & 134.1 \\
& 25 & 286 & 31.7 & 134.8 \\
& 50 & 255 & 27.1 & 135.7 \\
& 75 & 192 & 18.4 & 138.3 \\
\hline & 100 & 121 & 8.40 & 130.3 \\
& 0 & 277 & 21.7 & 131.2 \\
& 10 & 251 & 19.5 & 132.3 \\
& 15 & 250 & 19.3 & 133.9 \\
& 25 & 240 & 19.7 & 135.1 \\
& 50 & 205 & 15.2 & 138.0 \\
\hline
\end{tabular}

For using in non-food contact bottles, the materials need to keep the stiffness and a high impact strength and environmental stress cracking resistances. For these reasons, tensile, flexural and impact test were performed for all blends. Additionally, the resistance to environmental stress cracking (ESCR) was measured to evaluate the influence of the recycled material into this critical parameter for packaging applications. The values obtained in all tests were compared with the standard values for common raw HDPEs used for packaging applications. Reference values indicated in Figure 6, as dot lines, were obtained as an average of different blow molding HDPE commercial bottles.

Figure $6 \mathrm{a}, \mathrm{b}$ depicts a comparative of yield strength and elongation at break values obtained for all prepared systems. For yield strength and elongation at break, reference values are $26 \mathrm{MPa}$ and $700 \%$, respectively. Both properties are influenced by the incorporation of recycled resin into the blend, decreasing as the rFN content is higher, which results in the reduction of the Mw of the material. Nevertheless, for PE4 and PE5 systems contents up to $50 \%$ of recycled material makes the values remaining above or around the threshold. The higher Mw of both virgin resins allows incorporating more recycled material into the blend.

Regarding flexural modulus, the reference value must be closer to $1150 \mathrm{MPa}$ to guarantee the minimum stiffness required for the bottles. As it can be seen in Figure 6c, all virgin and recycled resins have similar values. PE4 and PE5 have slightly lower rigidity, but with the increasing content of $\mathrm{rFN}$ the flexural modulus slightly increases. All blends with a $50 \mathrm{wt} . \%$ content of recycled material have values above the $1150 \mathrm{MPa}$, thus the stiffness is not a restriction for the use of this recyclate for packaging application. 

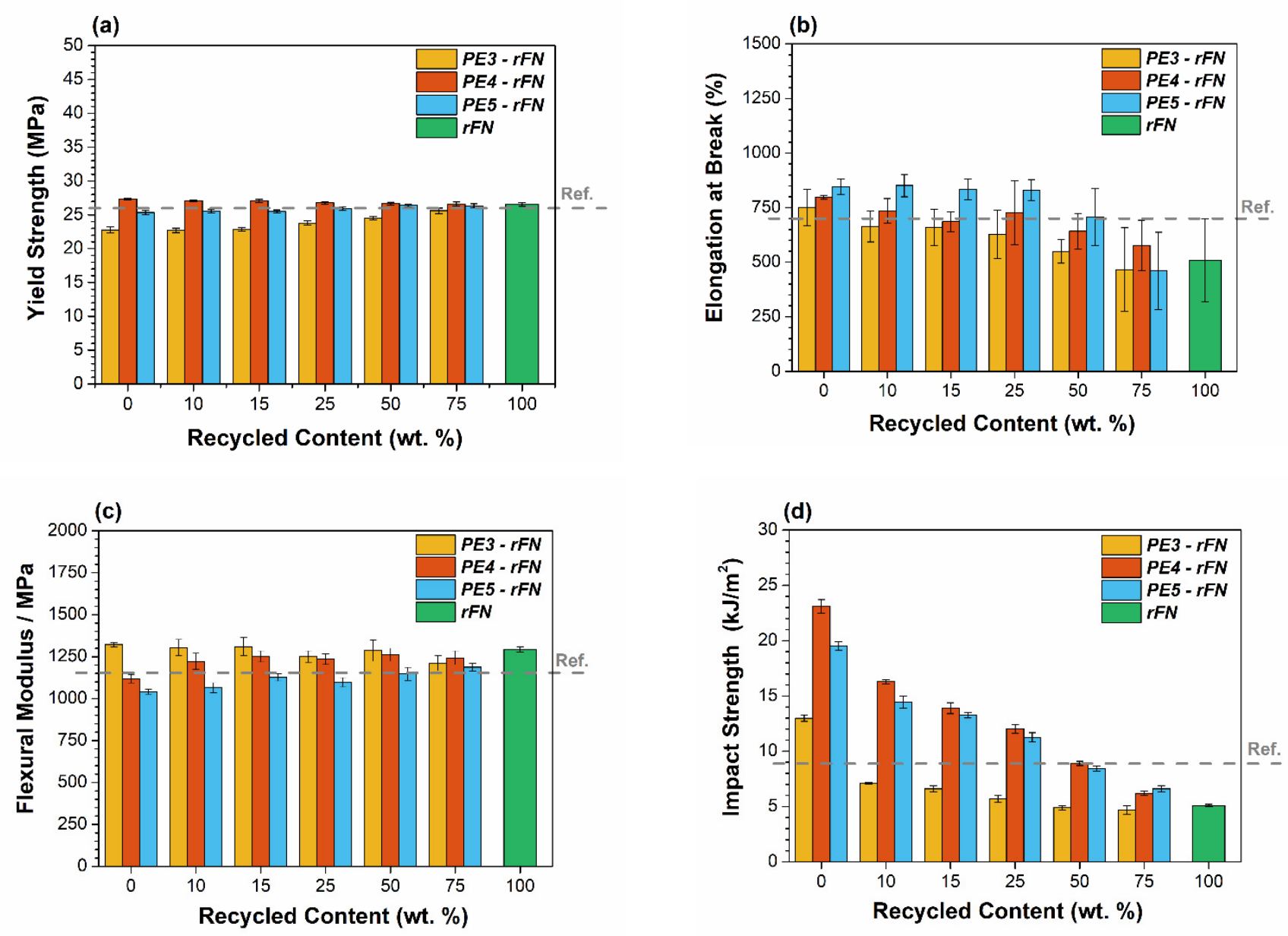

Figure 6. (a) Yield strength, (b) Elongation at break, (c) Flexural modulus and (d) Impact strength resistance results for PE3-PE4 and PE5-rFN blend systems.

Figure $6 \mathrm{~d}$ also shows the impact resistance for the different blend systems analyzed. The impact strength is the most sensitive mechanical property to the recycled content and for the different blends is critically influenced by the low impact resistance of the rFN resin, around $5 \mathrm{~kJ} / \mathrm{m}^{2}$. Minimum required impact resistance needs to be above $9 \mathrm{~kJ} / \mathrm{m}^{2}$, value not reached for any blends of system PE3-rFN. The Mw of the raw resin critically mediates on the impact strength resistance of the systems, which rapidly decrease with the incorporation of rFN. However, results are improved when higher Mw resins such as PE4 and PE5, are used. Both systems allow reaching a recycled content of up to $50 \mathrm{wt} . \%$, maintaining the minimum specifications. The higher Mw of PE4 and PE5 raw resins increases the overall impact resistance of the material, as a higher degree of entanglement and tie molecules density difficult the rupture of PE bonds and the fracture process, allowing the material to absorb more energy. The impact resistance falls dramatically with the increment of the recycled resin, as the rFN has almost half the Mw of the virgin resins. Additionally, degradation and inorganic impurities make the rFN more brittle, which lower the impact of the material after the blending process.

Finally, the environmental stress cracking resistance (ESCR) has been evaluated. This long-term mechanical property is crucial for the application considered, as in the presence of stress cracking agents, such as detergents or alcohols, PE suffers breakage after an interval of time $[43,44]$. Results for $\mathrm{rFN}$ show a low resistance to ESCR $(\sim 10 \mathrm{~h})$. This recyclate has a low $\mathrm{Mw}$, a property that greatly influences the environmental stress cracking resistance of PE materials. Moreover, the presence of inorganic impurities, previously detected, together with a certain level of degradation caused during the recycling process $[45,46]$ also determines the lower ESCR performance of the rFN. On the other hand, raw resins 
PE3, PE4 and PE5 have overall higher ESCR values due to its high Mw, which helps to increase the tie molecular density [47-49].

As shown in Figure 7, the same trend is observed for all blend systems. As the content of recycled resin increases the ESCR of each blend exponentially decreases, even at low contents of recyclate. When PE3 is used as a raw material, only $25 \mathrm{wt} . \%$ of $\mathrm{rFN}$ could be incorporated into the blend in order to fulfill the resistance for packaging applications, fixed at a threshold value of $70 \mathrm{~h}$ from commercial HDPEs used as reference. The loss of ESCR properties, promoted by the incorporation of $\mathrm{rFN}$ in the blends, can be compensated and commensurate with raw resins with higher Mw, such as PE4 or PE5 resins. Thus, higher ESCR values are achieved when PE5 is chosen as raw resin. This could be explained because of the higher SCB content of PE5 (Table 1), which in the case of the blends is mainly located in the high-molecular weight region, and therefore increasing the ESCR performance of the material [47]. In this way, it is possible to incorporate up to $50 \%$ of recycled resin in the PE5 - rFN system, guaranteeing the standard value of the commercial reference materials $(70 \mathrm{~h})$.

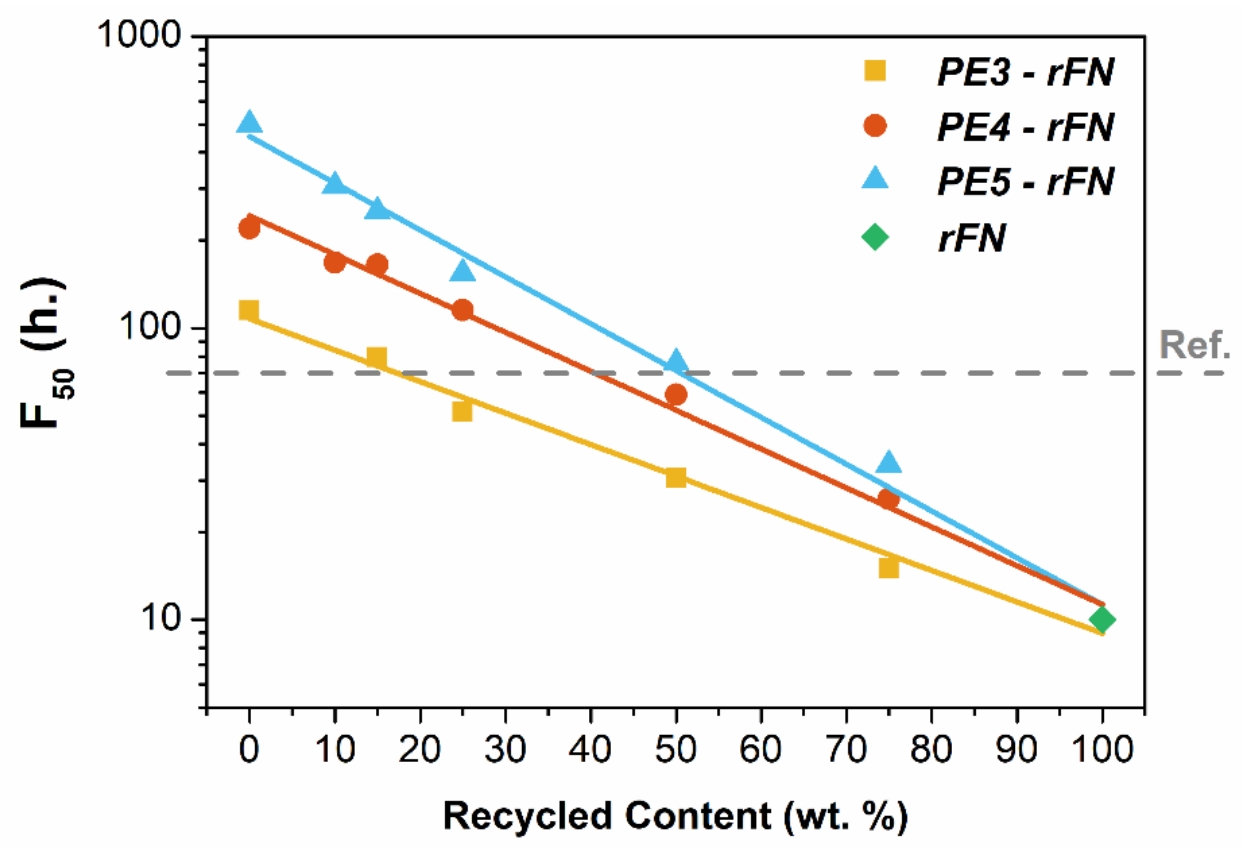

Figure 7. ESCR $\mathrm{F}_{50}$ values (h) vs. recycled content for all blends.

Finally, for PE5-rFN system, which shows the best results in terms of mechanical and ESCR properties, a molecular model has been introduced to confirm the miscibility of the blend components from a morphological point of view. The double reptation model [50] for miscible blends, as expressed in Equation (1), is frequently applied to explain the viscoelastic behavior of polyolefin melts [51,52]. Indeed, rheology has become a potent tool for inferring morphological state.

$$
G(t)=\left[\sum_{i} \phi_{i} G_{i}^{1 / c}(t)\right]^{2}
$$

Figure 8 represents the viscoelastic function $\tan \delta$, which is the ratio between loss and storage shear moduli $\left(\tan \delta=G^{\prime \prime} / G^{\prime}\right)$. As it can be observed, this additive model perfectly predicts the experimental response up to $50 \%$ of recycled content, which confirms the good miscibility among the PE5 and rFN, despite the differences in molecular weight of both resins. For PE5-rFN—75, a slight deviation of the model is observed, which can be attributable to the presence of impurities, which are more noticeable when the rFN is the main component in the blends. 


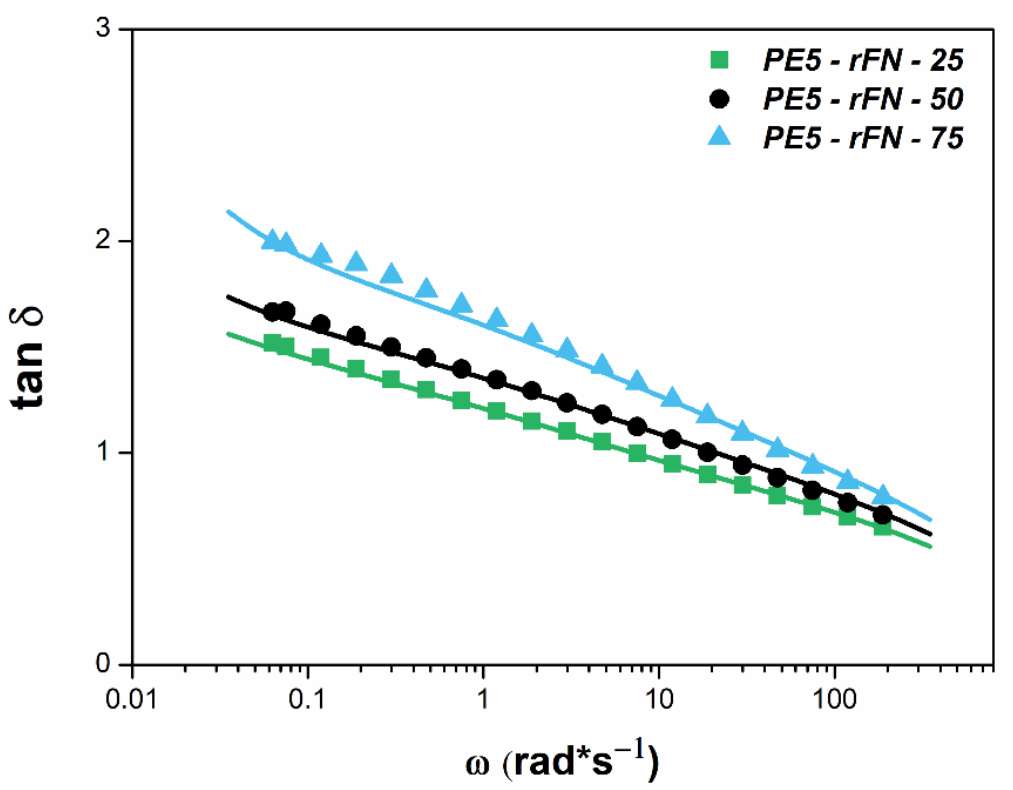

Figure 8. Tan $\delta$ versus the angular frequency for PE5-rFN system at $190{ }^{\circ} \mathrm{C}$. Solid lines represent the results of the additive model for miscible blends.

Blends that incorporate virgin PEs with higher Mw enhance the mechanical performance of the recycled PE, even with the presence of slight contents of impurities or contaminants, which seems to be a good alternative for this kind of recycled HDPE from fishing nets. These results could be further improved with better handling and management of the discarded fishing nets, which would enhance the properties of the recycled material and helping to its better recyclability, even for different applications than its original use, and thus closing the loop on discarded PE fishing nets.

\section{Conclusions}

Plastic pollution is becoming an increasing problem in our world, with the marine environments especially affected by plastic debris. Discarded fishing nets, particularly those made of polyolefins, are subjected to harsh conditions that affect its properties, lowering its value as recycled materials. To evaluate possible uses for this recycling stream, rFN has been blended with different raw resins. First, blends with virgin HDPE were explored to be used again for the manufacture of fishing nets. This study produced poor results, despite the good compatibility exhibited between virgin and recycled resins. Mechanical properties showed a high scatter in the results, especially due to the inorganic contaminants detected in the rFN, which made more difficult the obtention of fibers with proper quality to satisfy the demanding requirements for fishing nets. This result dramatically decreases its use on the original application.

As other possible applications for the rFN, the use of this material in the manufacture of non-food contact bottles has been explored. To strength the properties of the recyclate, rFN was blended with three different high-molecular blow molding virgin resins, to ensure the minimum requirements for the packaging application. Results show that while some properties are less influenced by the recycled content, other key properties such as impact strength or environmental stress cracking resistances rapidly decrease. However, when using raw resins with remarkably higher Mw than rFN, as PE4 or PE5 resins, the incorporation of up to $50 \mathrm{wt} . \%$ of recycled material that meets the specifications was achieved. In this sense, it has been proven that is critical to know the properties of the recyclate to identify its possible uses. Additionally, a proper selection of virgin materials helps to compensate the loss of properties of the recycled materials and open up the way to new applications different from the original. The approach herein developed can help 
in the design of new products, as crucial step for the growth of a resilient and sustainable industry of plastics, in line with the objectives pursued by the Circular Economy.

Author Contributions: R.J.: Investigation, Writing—original draft. C.D.: Conceptualization, Writingreview \& editing, Funding acquisition. N.R.: Investigation, Writing—review \& editing. B.P.: Writingreview \& editing. S.G.: Writing-review \& editing. R.A.G.-M.: Supervision, Conceptualization, Writing - review \& editing, Funding acquisition. All authors have read and agreed to the published version of the manuscript.

Funding: This research did not receive any specific grant from funding agencies in the public, commercial, or not-for-profit sectors.

Institutional Review Board Statement: Not applicable.

Informed Consent Statement: Not applicable.

Data Availability Statement: Not applicable.

Acknowledgments: We acknowledge the Taller de Inyección de la Industria del Plástico (TIIP) from Zaragoza University for their support with blends preparation. We also especially acknowledge the technical staff of the Polymer Technology Laboratory (LATEP) for the great technical work and support.

Conflicts of Interest: The authors declare no conflict of interest.

\section{References}

1. PlasticsEurope Plastics-the Facts 2020. Available online: https://www.plasticseurope.org/es/resources/publications/4312 - plastics-facts-2020 (accessed on 12 January 2021).

2. Barnes, D.K.A.; Galgani, F.; Thompson, R.C.; Barlaz, M. Accumulation and fragmentation of plastic debris in global environments. Philos. Trans. R. Soc. B-Biol. Sci. 2009, 364, 1985-1998. [CrossRef] [PubMed]

3. Lebreton, L.; Slat, B.; Ferrari, F.; Sainte-Rose, B.; Aitken, J.; Marthouse, R.; Hajbane, S.; Cunsolo, S.; Schwarz, A.; Levivier, A.; et al. Evidence that the Great Pacific Garbage Patch is rapidly accumulating plastic. Sci. Rep. 2018, 8, 4666. [CrossRef] [PubMed]

4. Peng, L.; Fu, D.; Qi, H.; Lan, C.Q.; Yu, H.; Ge, C. Micro- and nano-plastics in marine environment: Source, distribution and threats-A review. Sci. Total Environ. 2020, 698. [CrossRef] [PubMed]

5. Lau, W.W.Y.; Shiran, Y.; Bailey, R.M.; Cook, E.; Stuchtey, M.R.; Koskella, J.; Velis, C.A.; Godfrey, L.; Boucher, J.; Murphy, M.B.; et al. Evaluating scenarios toward zero plastic pollution. Sci. 2020, 369, 1455-1461. [CrossRef]

6. Sherrington, C. Plastics in the Marine Environment; Eunomia Research \& Consulting Ltd.: Bristol, UK, 2016.

7. Jambeck, J.; Hardesty, B.D.; Brooks, A.L.; Friend, T.; Teleki, K.; Fabres, J.; Beaudoin, Y.; Bamba, A.; Francis, J.; Ribbink, A.J.; et al. Challenges and emerging solutions to the land-based plastic waste issue in Africa. Mar. Policy 2018, 96, 256-263. [CrossRef]

8. Wichai-utcha, N.; Chavalparit, O. 3Rs Policy and plastic waste management in Thailand. J. Mater. Cycles Waste Manag. 2019, 21, 10-22. [CrossRef]

9. Georg, H.; Dennis, W.; Willem, V.; Anna, A.; Alberto, B.; María, D.C.M.; Eugenia, M.J.M.; Vinci, M.; Giorgetti, A. EU Marine Beach Litter Baselines 2019. Available online: https:/ / mcc.jrc.ec.europa.eu/main/dev.py? $\mathrm{N}=41 \& \mathrm{O}=452$ (accessed on 29 July 2021).

10. Macfadyen, G.; Huntington, T.; Cappell, R. Abandoned, Lost or Otherwise Discarded Fishing Gear; UNEP/FAO, Ed.; UNEP/FAO: Lymington, UK, 2009; ISBN 978-92-5-106196-1.

11. Richardson, K.; Wilcox, C.; Vince, J.; Hardesty, B.D. Challenges and misperceptions around global fishing gear loss estimates. Mar. Policy 2021, 129, 104522. [CrossRef]

12. De Sa, L.C.; Oliveira, M.; Ribeiro, F.; Rocha, T.L.; Futter, M.N. Studies of the effects of microplastics on aquatic organisms: What do we know and where should we focus our efforts in the future? Sci. Total Environ. 2018, 645, 1029-1039. [CrossRef]

13. Wright, S.L.; Thompson, R.C.; Galloway, T.S. The physical impacts of microplastics on marine organisms: A review. Environ. Pollut. 2013, 178, 483-492. [CrossRef]

14. Beaumont, N.J.; Aanesen, M.; Austen, M.C.; Borger, T.; Clark, J.R.; Cole, M.; Hooper, T.; Lindeque, P.K.; Pasco, C.; Wyles, K.J. Global ecological, social and economic impacts of marine plastic. Mar. Pollut. Bull. 2019, 142, 189-195. [CrossRef]

15. Xanthos, D.; Walker, T.R. International policies to reduce plastic marine pollution from single-use plastics (plastic bags and microbeads): A review. Mar. Pollut. Bull. 2017, 118, 17-26. [CrossRef] [PubMed]

16. Pinto da Costa, J.; Rocha-Santos, T.; Duarte, A.C. The Environmental Impacts of Plastics and Micro-Plastics Use, Waste and Pollution: EU and National Measures; European Union: Brussels, Belgium, 2020.

17. Li, W.C.; Tse, H.F.; Fok, L. Plastic waste in the marine environment: A review of sources, occurrence and effects. Sci. Total Environ. 2016, 566, 333-349. [CrossRef] [PubMed]

18. Mondragon, G.; Kortaberria, G.; Mendiburu Valor, E.; González, N.; Arbelaiz, A.; Peña, C. Thermomechanical recycling of polyamide 6 from fishing nets waste. J. Appl. Polym. Sci. 2019, 137, 48442. [CrossRef] 
19. Mihut, C.; Captain, D.K.; Gadala-Maria, F.; Amiridis, M.D. Review: Recycling of nylon from carpet waste. Polym. Eng. Sci. 2001, 41,1457-1470. [CrossRef]

20. Charter, M.; Soren, J.; Carruthers, R. Products from Waste Fishing Nets; The Centre for Sustainable Design: Farnham, UK, 2018.

21. Coe, J.M.; Bunn, A.R. National Oceanic and Atmospheric Administration Research on the Use of Degradable Fishing Gear and Packaging Materials; Northwest and Alaska Fisheries Center: Seattle, WA, USA, 1987.

22. Andrady, A.L. Microplastics in the marine environment. Mar. Pollut. Bull. 2011, 62, 1596-1605. [CrossRef]

23. Feary, D.; Aranda, M.; Russell, J.; Cabezas, O.; Rodríguez Climent, S.; Bremner, J. Study on Circular Design of the Fishing Gear for Reduction of Environmental Impacts; European Commision: Brussels, Belgium, 2020. [CrossRef]

24. Bertelsen, I.M.G.; Ottosen, L.M. Reuse of polyethylene fibres from discarded fishing nets as reinforcement in gypsym-based materials. Acad. J. Civ. Eng. 2017, 35, 545-548. [CrossRef]

25. Sato, T.; Shishido, M. Mechanical and structural properties for recycled thermoplastics from waste fishing ropes. J. Mater. Cycles Waste Manag. 2020, 22, 1682-1689. [CrossRef]

26. Truong, V.D.; Kim, M.O.; Kim, D.J. Feasibility study on use of waste fishing nets as continuous reinforcements in cement-based matrix. Constr. Build. Mater. 2021, 269, 121314. [CrossRef]

27. Monteiro, D.; Rangel, B.; Alves, J.; Teixeira, A. Design as a vehicle for using waste of fishing nets and ropes to create new products. Eng. Soc. 2016, $2016,67$.

28. Zylberberg, N. PLASTIX Creates New Material from Used Maritime Gear. Available online: https://medium.com/2030magazine/ plastix-creates-new-material-from-ghost-nets-d9ce9ee4ca83 (accessed on 1 June 2021).

29. NetPlus ${ }^{\circledR}$ Recycled Fishing Nets. Available online: https:/ / www.patagonia.com/our-footprint/netplus-recycled-fishing-nets.html (accessed on 5 July 2021).

30. Vilaplana, F.; Karlsson, S. Quality Concepts for the Improved Use of Recycled Polymeric Materials: A Review. Macromol. Mater. Eng. 2008, 293, 274-297. [CrossRef]

31. Juan, R.; Domínguez, C.; Robledo, N.; Paredes, B.; García-Muñoz, R.A. Incorporation of recycled high-density polyethylene to polyethylene pipe grade resins to increase close-loop recycling and Underpin the circular economy. J. Clean. Prod. 2020, 276, 124081. [CrossRef]

32. Istrate, I.-R.; Juan, R.; Martin-Gamboa, M.; Domínguez, C.; García-Muñoz, R.A.; Dufour, J. Environmental life cycle assessment of the incorporation of recycled high-density polyethylene to polyethylene pipe grade resins. J. Clean. Prod. 2021, $319,128580$. [CrossRef]

33. Al-Salem, S.M.; Lettieri, P.; Baeyens, J. Recycling and recovery routes of plastic solid waste (PSW): A review. Waste Manag. 2009, 29, 2625-2643. [CrossRef]

34. Welden, N.A.; Cowie, P.R. Degradation of common polymer ropes in a sublittoral marine environment. Mar. Pollut. Bull. 2017, 118, 248-253. [CrossRef] [PubMed]

35. Gall, M.; Freudenthaler, P.; Fischer, J.; Lang, R. Characterization of Composition and Structure-Property Relationships of Commercial Post-Consumer Polyethylene and Polypropylene Recyclates. Polymers (Basel) 2021, 13, 1574. [CrossRef] [PubMed]

36. Messiha, M.; Frank, A.; Koch, T.; Arbeiter, F.; Pinter, G. Effect of polyethylene and polypropylene cross-contamination on slow crack growth resistance. Int. J. Polym. Anal. Charact. 2020, 25, 649-666. [CrossRef]

37. Gulmine, J.V.; Janissek, P.R.; Heise, H.M.; Akcelrud, L. Polyethylene characterization by FTIR. Polym. Test. 2002, 21, 557-563. [CrossRef]

38. Schindler, A.; Doedt, M.; Gezgin, Ş.; Menzel, J.; Schmölzer, S. Identification of polymers by means of DSC, TG, STA and computer-assisted database search. J. Therm. Anal. Calorim. 2017, 129, 833-842. [CrossRef]

39. Juan, R.; Paredes, B.; García-Muñoz, R.A.; Domínguez, C. Quantification of PP contamination in recycled PE by TREF analysis for improved the quality and circularity of plastics. Polym. Test. 2021, 100, 107273. [CrossRef]

40. Fernández, A.; Expósito, M.T.; Peña, B.; Berger, R.; Shu, J.; Graf, R.; Spiess, H.W.; García-Muñoz, R.A. Molecular structure and local dynamic in impact polypropylene copolymers studied by preparative TREF, solid state NMR spectroscopy, and SFM microscopy. Polymers (Guildf) 2015, 61, 87-98. [CrossRef]

41. European Union A European Strategy for Plastics in a Circular Economy. Available online: https:/ / publications.europa.eu/s/kIT6 (accessed on 28 September 2019).

42. Schyns, Z.O.G.; Shaver, M.P. Mechanical Recycling of Packaging Plastics: A Review. Macromol. Rapid Commun. 2021, $42,2000415$. [CrossRef]

43. Brown, H.R. A theory of the environmental stress cracking of polyethylene. Polymers (Guildf) 1978, 19, 1186-1188. [CrossRef]

44. Hittmair, P.; Ullman, R. Environmental stress cracking of polyethylene. J. Appl. Polym. Sci. 1962, 6, 1-14. [CrossRef]

45. Vogt, B.D.; Stokes, K.K.; Kumar, S.K. Why is Recycling of Postconsumer Plastics so Challenging? ACS Appl. Polym. Mater. 2021, 3, 4325-4346. [CrossRef]

46. Benoit, N.; González-Núñez, R.; Rodrigue, D. High Density Polyethylene Degradation Followed by Closed-loop Recycling. Prog. Rubber Plast. Recycl. Technol. 2017, 33, 17-38. [CrossRef]

47. García, R.; Carrero, A.; Aroca, M.; Prieto, O.; Domínguez, C. Slow crack growth resistance in resin blends of chromium and metallocene catalyzed ethylene-hexene copolymers for pipe applications. Polym. Eng. Sci. 2008, 48, 925-933. [CrossRef]

48. García, R.A.; Carrero, A.; Martín, C.; Domínguez, C. Effects of the structural components on slow crack growth process in polyethylene blends. Composition intervals prediction for pipe applications. J. Appl. Polym. Sci. 2011, 121, 3269-3276. [CrossRef] 
49. Adib, A.; Domínguez, C.; Rodríguez, J.; Martín, C.; García, R.A. The effect of microstructure on the slow crack growth resistance in polyethylene resins. Polym. Eng. Sci. 2015, 55, 1018-1023. [CrossRef]

50. Tsenoglou, C. Molecular weight polydispersity effects on the viscoelasticity of entangled linear polymers. Macromolecules 1991, 24, 1762-1767. [CrossRef]

51. Groves, D.J.; McLeish, T.C.B.; Chohan, R.K.; Coates, P.D. Predicting the rheology of linear with branched polyethylene blends. Rheol. Acta 1996, 35, 481-491. [CrossRef]

52. Robledo, N.; Vega, J.F.; Nieto, J.; Martínez-Salazar, J. The role of the interface in melt linear viscoelastic properties of LLDPE/LDPE blends: Effect of the molecular architecture of the matrix. J. Appl. Polym. Sci. 2009, 114, 420-429. [CrossRef] 